\title{
Carbohydrate digestion and release of pancreatic polypeptide in health and diabetes mellitus
}

P LAYER, V L W GO, AND E P DIMAGNO

From the Division of Gastroenterology and GI Research Unit, Mayo Clinic and Foundation, Rochester, MN, USA.

SUMMARY The effects of meal volume and luminal digestion of carbohydrates on the release of pancreatic polypeptide (HPP) were investigated in eight healthy subjects and in six patients who had non-insulin dependent diabetes mellitus. On one occasion each subject ingested a placebo with 200 $\mathrm{ml}$ water and a starch $(50 \mathrm{~g})$ pudding meal $(400 \mathrm{ml}) 30$ minutes later. On another occasion an amylase inhibitor that retards intraluminal starch digestion was given with the water and starch. In normal subjects, water caused a moderate rise in HPP plasma levels $(16.9(10.9) \mathrm{pg} / \mathrm{ml} ; \mathrm{p}<0.02)$ and ingestion of starch increased HPP in a double peaked pattern. The mean increments of the peaks were $45 \cdot 0(15 \cdot 2) \mathrm{pg} / \mathrm{ml}(\mathrm{p}<0 \cdot 02)$ and $41 \cdot 1(17 \cdot 3) \mathrm{pg} / \mathrm{ml}(\mathrm{p}<0 \cdot 05)$, respectively. In the diabetic subjects, the HPP concentrations did not increase in response to water. After ingestion of starch the diabetics had two peaks of HPP that were similar in magnitude, but the early postprandial peak was delayed significantly compared to normal subjects $(37.5(5.1) \mathrm{min} v 23.4(3.9) \mathrm{min} ; \mathbf{p}<0.05)$. The amylase inhibitor $(5$ or $10 \mathrm{~g})$ reduced the early postprandial HPP peak by $79 \%(p<0 \cdot 05)$ in normal subjects and $4 \mathrm{~g}$ of the inhibitor reduced the early HPP peak by $58 \%(p<0 \cdot 05)$ in the diabetics. In both groups ingestion of the amylase inhibitor abolished the late HPP peak $(p<0 \cdot 05)$. In conclusion, carbohydrate induced HPP release is dependent on undisturbed intraluminal starch digestion.

Human pancreatic polypeptide (HPP) is a 36 -amino acid polypeptide formed mainly in the pancreas. ${ }^{12}$ The physiological role of HPP is uncertain, but it is probably involved in the regulation of pancreatic function. Postprandially, HPP is released by stimuli including cephalic stimulation, gut distension and presence of nutrients in the gastrointestinal lumen.

While it is assumed that cephalic or distension induced HPP release is exclusively or mainly mediated by the vagus, regulation of nutrient induced HPP release is less well understood. ${ }^{3}$ For example, it is unknown whether digestion of nutrients within the gut lumen is necessary to release HPP from the pancreas postprandially.

Our aims were to determine if HPP is released by a non-caloric volume stimulus (water) or intraluminal digestion of carbohydrate in healthy volunteers and in subjects with diabetes mellitus. The response to

Address for correspondence: E P DiMagno. MD, GI Diagnostic Unit, Mayo Clinic, Rochester, MN 55905, USA.

Accepted for publication 31 January 1989. reduced and normal rates of intraluminal carbohydrate digestion were measured by giving a starch meal with and without an amylase inhibitor that decreases starch digestion. ${ }^{4}$

\section{Methods}

SUBJECTS

The protocol was approved by the Mayo Institutional Review Board and informed written consent was obtained from all participants. Eight normal subjects (five men, age range 19 to 47 years) and six diabetic patients (four men, age range 53 to 65 years) participated in this study. Each patient had the onset of noninsulin-dependent diabetes mellitus (type II) after the age of 40 years which was present for eight to 29 (mean 17.8) years. No patient had a history of ketoacidosis nor clinical evidence of autonomic or somatic neuropathy or other diabetic complications (history, physical examination). All of the patients met the National Diabetes Data Group criteria for non-insulin-dependent (type II) diabetes mellitus. ${ }^{5}$ Each normal and diabetic subject was an $\mathrm{H}_{2}$ producer 
in response to malabsorbed carbohydrate. One week before the study each subject had a breath $\mathrm{H}_{2}$ response of $>10 \mathrm{ppm}$ over baseline in response to ingesting $20 \mathrm{~g}$ of lactulose.

EXPERIMENTAL DESIGN

In each subject the HPP response to a test meal was determined on two separate days. The test meal consisted of two courses. The first course was $200 \mathrm{ml}$ water. The second course, given 30 min later, was 400 $\mathrm{ml}$ pure starch pudding that contained $50 \mathrm{~g}$ rice starch.

On one occasion, the test meal was administered without, and on the other occasion with a specific, inhibitor of human salivary and pancreatic $\alpha$ amylases $^{6}$ that we purified from Great Northern white beans. ' Ingestion of 4 to $10 \mathrm{~g}$ of this inhibitor with $50 \mathrm{~g} \operatorname{starch}^{78} 2 \cdot 9^{9}$ to $6 \cdot 0^{10} \mathrm{~g}$ with mixed carbohydrate, fat and protein meals or perfusion of 2 to $5 \mathrm{mg}$ per $\mathrm{ml}$ into the duodenum ${ }^{7}$ causes $>95 \%$ inhibition of pancreatic amylase secretion, decreases intraluminal digestion of starch in the human small intestine and reduces postprandial glycaemia. Five or $10 \mathrm{~g}$ of the inhibitor was given to normal subjects $(\mathrm{n}=4$ each) and $4 \mathrm{~g}$ was given to diabetic subjects $(n=6) ; 20 \%$ of the total inhibitor dose was added to the water and $80 \%$ to the starch pudding. The lower dose in diabetics was chosen because in normal subjects both inhibitor doses had similar effects of intaluminal amylase activity and starch digestion as well as postprandial glycaemia, but caused dose dependent diarrhoea. ${ }^{+8}$ Further, in diabetics the $4 \mathrm{~g}$ dose significantly reduced postprandial glucose, but caused less gastrointestinal symptoms than the high doses. "1"

Blood samples were taken before water was ingested, before the starch was ingested and postprandially every quarter hour for the first 90 minutes, every half hour from 90 to 300 minutes and hourly from 300 to 420 minutes. To avoid cephalic stimulation of HPP release, water drinks and starch meals were kept in a separate room and only taken into the study area immediately before their ingestion. End expiratory breath samples were taken every 15 minutes throughout the experiment.

ANALYSES AND STATISTICS

Plasma concentrations of HPP were measured by radioimmunoassay as previously described. ${ }^{\text {" Breath }}$ $\mathrm{H}_{2}$ concentrations were assessed by gas chromotography as previously reported. ${ }^{*}$

Within each group the effect of water (volume) was assessed by subtracting preprandial values from the values obtained 30 minutes after water ingestion (immediately before ingestion of the starch meal) and evaluating the difference by paired $t$ tests. The effects of the amylase inhibitor on the response to water was assessed by comparing the increments obtained for the placebo studies with the increments obtained with the inhibitor by using paired $t$ tests. ${ }^{12}$ Ingestion of the starch pudding regularly induced a double peaked increase in HPP levels with an early peak within the first postprandial hour, and a later peak between three and five hours postprandially. Thus, to assess the early increase in HPP levels, prestarch values were subtracted from poststarch values, and increments were integrated over the first hour after starch ingestion. Similarly, to assess the late increase, integrated increments were calculated for the period between 180 and $300 \mathrm{~min}$ after starch ingestion. These integrated responses were compared for placebo and inhibitor studies by using paired $t$ tests." Because the two inhibitor doses used in normal subjects had virtually identical effects, overall effects of both doses are presented unless indicated otherwise. Time intervals to HPP peaks were compared for normal subjects and diabetics by using unpaired $t$ tests. ${ }^{2}$ Data are presented as mean (SE).

\section{Results}

NORMAL SUBJECTS

Fasting levels of HPP did not differ significantly before ingestion of the test meals with placebo $(77 \cdot 6$ $(10 \cdot 8) \mathrm{pg} / \mathrm{ml})$ or amylase inhibitor $(51 \cdot 2(8 \cdot 3) \mathrm{pg} / \mathrm{ml})$. Water without amylase inhibitor induced a moderate rise in mean HPP of $16.9(10.9) \mathrm{pg} / \mathrm{ml}(22 \%)$ over the preprandial level $(\mathrm{p}<0 \cdot 02 ;$ Fig. 1, left panel $)$.

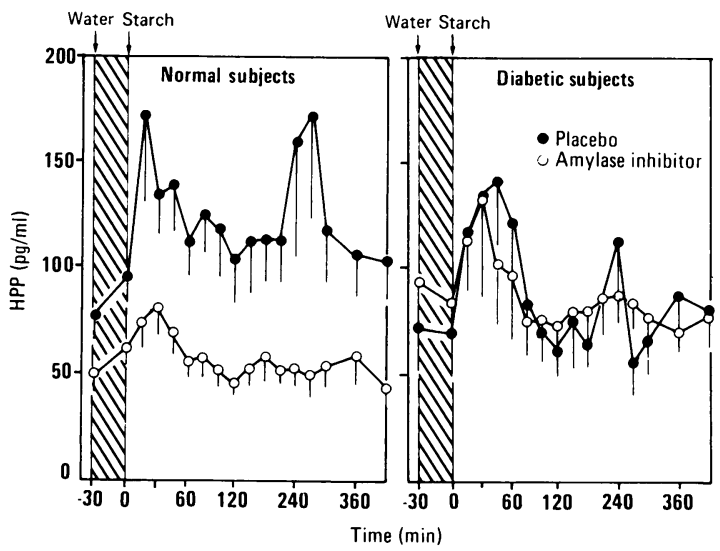

Fig. 1 Left panel: Plasma HPP concentrations before ingestion of water (first arrow) and starch (second arrow) without (closed symbols) or with (open symbols) amylase inhibitor in normal subjects. Mean of $n=8$ experiments (SE). Right panel: Plasma HPP concentrations before ingestion of water (first arrow) and starch (second arrow) without (closed symbols) or with (open symbols) amylase inhibitor in diabetic subjects. Mean of $n=8$ experiments (SE). 
Ingestion of the starch pudding subsequently caused a double peaked increase in HPP concentrations (Fig. 1, left panel). The mean of maximal HPP levels during the first hour (early peak) was 190.6 (43.2) $\mathrm{pg} / \mathrm{ml}$ and this peak occurred 15 to 45 min (mean 23.4 (3.9) min) postprandially. The mean increment during the first hour following starch ingestion was $45.0(15 \cdot 2) \mathrm{pg} / \mathrm{ml}(\mathrm{p}<0 \cdot 02$; Fig. 2, left panel). Mean HPP values of the second peak which occurred during the fourth and fifth hours (mean 227 (17) min) were similar to the values of the first peak (peak concentration $=221.5(60.6) \mathrm{pg} / \mathrm{ml}$; mean increment $=41 \cdot 1(17 \cdot 3) \mathrm{pg} / \mathrm{ml} ; \mathrm{p}<0.05 v$ preprandial and the second and third postprandial hours; (Fig. 2, left panel). Ingestion of the placebo meal did not induce a significant increase in breath $\mathrm{H}_{2}$ above preprandial concentrations $(7 \cdot 8(1 \cdot 1) \mathrm{ppm})$.

Ingestion of water and the ingestion of the combination of water and the amylase inhibitor was associated with a similar rise in HPP over preprandial levels (Fig. 2, left panel). By contrast, addition of the amylase inhibitor to the starch pudding decreased $(p<0.05)$ the integrated HPP response during the first hour by $79 \%$ and completely abolished the late peak. Breath $\mathrm{H}_{2}$ levels increase significantly in response to the starch meal with amylase inhibitor (from 5.8(0.9) ppm to 21.3(3.6) ppm; $<<0 \cdot 001$ ).

\section{DIABETIC SUBJECTS}

In diabetics, consumption of $200 \mathrm{ml}$ water did not alter fasting HPP levels (70.6 (20.4) v $72.6(21.4)$ $\mathrm{pg} / \mathrm{ml}$; Fig. 1, right panel). Ingestion of the starch pudding induced a double peaked response, but the first peak occurred after $37.5(5 \cdot 1) \mathrm{min}$, which was significantly later than in normal subjects $(p<0 \cdot 05)$. The mean of the maximal HPP concentration of each diabetic patient during the first hour (the first peak) was $150.0(34.5) \mathrm{pg} / \mathrm{ml}(\mathrm{p}<0.005 v$ preprandial $)$ and the mean increment over prestarch concentration during the first hour after starch ingestion was $60 \cdot 2$ $(10.4) \mathrm{pg} / \mathrm{ml}$ (Fig. 2, right panel). Similar to normal subjects, diabetics had a second peak that occurred after 223 (10) min (Fig. 1, right panel) and had a mean peak concentration of $116.8(27.2) \mathrm{pg} / \mathrm{ml}$ $(\mathrm{p}<0.01 v$ preprandial) and a mean increment of 24.0 (4.7) $\mathrm{pg} / \mathrm{ml}$ (Fig. 2, right panel) during the fourth and fifth hours. The placebo meal did not alter postprandial breath $\mathrm{H}_{2}$ concentrations compared to preprandial levels $(2 \cdot 3(0 \cdot 3) \mathrm{ppm})$.

The combination of water and amylase inhibitor did not raise HPP levels above fasting levels $(94.4$ $(20.8) v 83.8(22.4) \mathrm{pg} / \mathrm{ml}$; Fig. 2, right panel). As in the normal subjects, HPP concentration in response to starch was significantly decreased by the inhibitor (Figs 1 and 2, right panels). The mean increment during the first hour was reduced by $58 \%(p<0.05$;

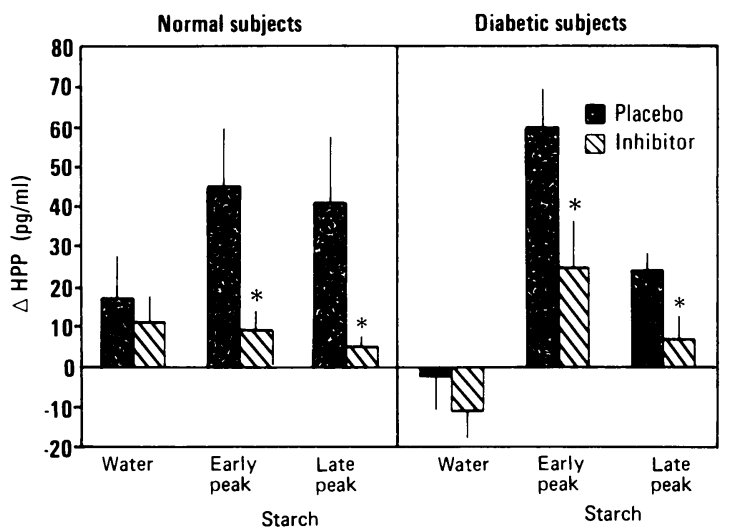

Fig. 2 Left panel: Increment response of plasma HPP to ingestion of water (left) and starch (middle: mean integrated increment during the first $60 \mathrm{~min}$ after starch; right: mean integrated increment during the fourth and fifth hours following starch), without (hatched bars) or with (gray bars) amylase inhibitors in normal subjects. ${ }^{*} p<0.05 \mathrm{v}$ placebo.

Right panel: Increment response of plasma HPP to ingestion of water (left) and starch (middle: mean integrated increment during the first $60 \mathrm{~min}$ after starch; right: mean integrated increment during the fourth and fifth hours following starch), without (hatched bars) or with (gray. bars) amylase inhibitor in diabetic subjects. ${ }^{*} p<0.05$ v placebo.

Fig. 2, right panel) and the late peak was abolished. With amylase inhibitor, there was a slight, but significant, increase in postprandial breath $\mathrm{H}_{2}$ concentrations (from $2.0(0.2) \mathrm{ppm}$ to $6.8(2.0) \mathrm{ppm}$; $\mathrm{p}<0 \cdot(05)$.

\section{Discussion}

In healthy subjects HPP plasma concentrations increased slightly in response to the volume load and increased markedly in a double peaked pattern in response to the starch meal. In comparison with healthy subjects, patients with longstanding type II diabetes mellitus had a diminished or absent HPP response to the non-caloric volume stimulus and a quantitatively normal, but delayed carbohydrate induced first peak of HPP concentrations. When intraluminal carbohydrate digestion was inhibited, the postprandial response to starch was markedly reduced in both normals and diabetics. These findings suggest that different mechanisms mediate postprandial HPP release in response to the volume stimulus and the carbohydrate stimulus after ingestion of a carbohydrate meal.

Postprandial release of HPP has been assumed to be mediated mainly by vagal cholinergic ${ }^{1314}$ and partly by non-vagal cholinergic ${ }^{1516}$ pathways and elicited by mechanisms such as cephalic stimula- 
tion ${ }^{16}{ }^{17}$, gastroduodenal distension, ${ }^{n 1 \times-2}$ and presence of nutrients in the gastrointestinal lumen. ${ }^{.2-2 h}$ The initial rise in postprandial HPP concentration is believed to be secondary to gastroduodenal distension induced by the meal volume, mediated by a vagal reflex and to comprise approximately $10-20 \%$ of the overall postprandial HPP increase. ${ }^{3272 \mathrm{x}}$

Our observations that in normal subjects water alone and the starch meal with the amylase inhibitor induced an increase in HPP during the early postprandial phase are consistent with this hypothesis. However, as amylase inhibition markedly reduced the early peak and completely abolished the late peak of HPP we believe that intraluminal digestion of complex carbohydrate is a major factor for the intestinal phase of the HPP response to ingesting starch. We have previously shown that ingestion of the inhibitor delays the digestion of starch intraluminally. Consequently the absorption of carbohydrate is reduced and the postprandial rise in plasma glucose is decreased. Therefore, luminal generation of the products of carbohydrate digestion or the absorption or both are probably necessary for carbohydrate induced HPP release.

Previously it was observed that inhibition of intestinal disacchridase activity did not reduce the HPP response to a mixed meal. In that study, however, it is likely that non-carbohydrate nutrients within the duodenum masked any effects that carbohydrates may have on HPP release. ${ }^{29}$ As we detected no difference in HPP release between water induced HPP release and the amylase inhibitor in addition to water, we believe it is unlikely that the amylase inhibitor excited non-specific inhibitory effects on endogenous HPP release. Thus, our studies suggest that inhibition of carbohydrate digestion before the luminal generation of glucose reduces carbohydrate induced HPP release.

The results in the diabetic patients indicate that their quantitative HPP response to carbohydrate ingestion was similar to that observed in normal subjects, suggesting that their pancreatic capacity for HPP secretion is not grossly altered. Occurrence of the first HPP peak after carbohydrate ingestion, however, was significantly delayed compared with normal subjects. Because carbohydrate-induced HPP release is dependent on luminal carbohydrate digestion, this delay is probably a consequence of slowed luminal generation and absorption of glucose, most likely caused by retarded gastric emptying of ingested starch. This retardation could not have been caused by a decreased rate of luminal digestion due to impaired pancreatic enzyme secretion because end expiratory breath $\mathrm{H}_{2}$ concentration did not increase in response to the starch meal. Moreover, pancreatic secretory capacity must be reduced to less than $10 \%$ of normal to give rise to a discernable disturbance of digestion ${ }^{31.11}$ and our patients had no evidence of such severe exocrine pancreatic insufficiency.

A more likely explanation for the delay in postprandial HPP release in the diabetics is slower than normal gastric emptying of ingested starch. It is conceivable that a retardation of gastric emptying rate in patients with long standing diabetes may reflect an alteration in vagal function. ${ }^{32}$ This hypothesis is supported by the observation that ingestion of water, a non-caloric volume stimulus that in healthy individuals elicits a transient, brief 40-50 minute HPP release exclusively via vagal cholinergic pathways, ${ }^{33.4}$ did not produce an increase in plasma HPP levels in our diabetic subjects. As we did not test these patients for asymptomatic autonomic neuropathy, the question of whether these changes were, indeed, caused by subclinical alteration of the autonomic nervous system remains unanswered. There is evidence, however, that early, largely subclinical disturbances of certain vagal functions may occur in the course of diabetes mellitus. For example, it has been shown that the vagally mediated HPP release in response to hypoglycaemia is disturbed in diabetic patients with or without clinical signs of diabetic autonomic neuropathy ${ }^{35-11}$ and in patients with nondiabetic autonomic neuropathy. ${ }^{412}$ As we have shown previously that in normal subjects the starch meal used in this study evokes only mild reactive hypoglycaemia in the late postprandial period, and no hypoglycaemia in the late postprandial period in diabetic subjects, ${ }^{,}$it is unlikely that hypoglycaemia plays a major role in the generation of the late HPP peak.

In the presence of amylase inhibition, carbohydrate induced HPP release in diabetic patients was also significantly reduced compared with placebo. This reduction was less pronounced than in the experiments with normal subjects receiving larger inhibitor doses. Because carbohydrate malabsorption as assessed by postprandial $\mathrm{H}_{2}$ production was also smaller in the diabetic group, it is likely that these effects were a result of incomplete amylase inhibition in the patients receiving the $4 \mathrm{~g}$ dose.

Plasma concentrations of HPP are age related. Mean basal concentrations of HPP increase approximately $30 \mathrm{pg} / \mathrm{ml}$ per decade ${ }^{+3}$ and after oral glucose ingestion, elderly men and women have a higher concentration of HPP and a larger increase over basal levels, but the time to peak concentration is the same for both age groups and sexes." The trend towards higher basal concentrations and the increased concentration of HPP in the diabetic subjects compared with the normal subjects in response to the amylase inhibitor may have occurred because our diabetic patients were older. Nevertheless, despite the differ- 
ence between normal subjects and diabetics in response to the inhibitor, in both groups the amylase inhibitor reduced the HPP response to the starch meal indicating that carbohydrate induced HPP release is in part dependent upon the degree of carbohydrate digestion.

Humoral mediators such as cholecystokinin and gastric inhibitory polypeptide (GIP) also may be involved in regulating the intestinal phase of postprandial liberation of HPP. ${ }^{24+5-14}$ For example, physiological levels of GIP have been reported to release HPP in man via cholinergically controlled pathways. ${ }^{4751}$ Our observation that postprandial release of GIP after a carbohydrate meals is abolished when intraluminal starch digestion is slowed $^{4}$ is consistent with the hypothesis that GIP participates in the control of HPP release..$^{.70}$

In conclusion, the regulation of the intestinal phase of carbohydrate induced HPP release appears to be dependent upon the rate and completeness of carbohydrate digestion.

Supported in part by grant La483/2-2 from Deutsche Forschungsgemeinschaft (Peter Layer), CRC grant RR585 from the National Institutes of Health and the Mayo Foundation. The authors wish to thank Rodney J Sandberg and Karen J Bentley for skilful technical assistance and Linda $\mathrm{J}$ Bakken for preparing the manuscript.

\section{References}

1 Chance RE, Jones WE. Polypeptides from bovine, ovine, human, and porcine pancreas. United States Patent Office 1974; 842: 063.

2 Larsson LI, Sundler F, Hakason R. Pancreatic polypeptide-a postulated new hormone: identification of its cellular storage by light and electron microscopic immunocytochemistry. Diabetologia 1976; 12: 211-26.

3 Floyd JC. Pancreatic polypeptide. Clin Gastroenterol 1980; 9: 657-8.

4 Layer P, Zinsmeister AR, DiMagno EP. Effects of decreasing intraluminal amylase activity on starch digestion and postprandial gastrointestinal function in humans. Gastroenterology 1986; 61: 442-7.

5 National Diabetes Data Group. Classification and diagnosis of diabetes mellitus and other categories of glucose intolerance. Diabetes 1977; 26: 30-5.

6 Marshall JJ, Lauda CM. Purification and properties of phaseolamin, an inhibitor of alpha-amylase, from the kidney bean, Phaseolus vulgaris. J Biol Chem 1975; 250: 8030-7.

7 Layer P, Carlson GL, DiMagno EP. Partially purified white bean amylase inhibitor reduces starch digestion in vitro and inactivates intraduodenal amylase in humans. Gastroenterology 1985; 88: 1895-902.

8 Layer P, Rizza RA, Zinsmeister AR, Carlson GL, DiMagno EP. Effect of a purified amylase inhibitor on carbohydrate tolerance in normal subjects and patients with diabetes mellitus. Mayo Clin Proc 1986; 61: 442-7.

9 Boivin M, Zinsmeister AR. Go VLW. DiMagno EP. Effect of a purified amylase inhibitor on carbohydrate metabolism after a mixed meal in healthy humans. Mayo Clin Proc 1987; 62: 249-55.

10 Boivin M, Flourie B. Rizza RA, Go VLW, DiMagno EP. Gastrointestinal and metabolic effects of amylase inhibition in diabetes. Gastroenterology 1988: 94: 387-94.

11 Keane FB, DiMagno EP. Dozois RR. Go VLW. Relationships among canine interdigestive exocrine pancreatic and biliary flow. duodenal motor activity, plasma pancreatic polypeptide. and motilin. Gastroenterology 1980; 78: 310-6.

12 Box GEP, Hunter WG, Hunter JS. Factional designs at two levels. In: Statistics for experimenters New York: John Wilcy, 1978; 306-51

13 Schwartz TW. Rehfeld JF. Stadil F. Larsson LI, Chance RE. Moon N. Pancreatic polypeptide response to food in duodenal-uleer patients before and after vagotomy. Lancet 1976; i: 1102-5.

14 Schwartz TW, Holst JT, Fahrenkrug J. et al. Vagal, cholinergic regulation of pancreatic polypeptide secretion. J Clin Invest 1978; 61: 781.

15 Glaser B. Floyd JC Jr, Vinik AI, Fajans SS, Pck S. Evidence for extravagal cholinergic dependence of pancreatic polypeptide responses to beef ingestion in man. Clin Res 1979; 27: 366.

16 Taylor IL. Feldman M. Richardson CT, Walsh JH. Gastric and cephalic stimulation of human pancreatic polypeptide release. (jastroenterology 1978: 75: 432-7.

17 Schwartz TW, Stenquist B. Olbe L. Cephalic phase of pancreatic-polypeptide secretion studied by sham feeding in man. Scand J (jastroenterol 1979: 14: 313-20.

18 Taylor IL, Richardson CT, Feldman M, Walsh JH. Mechanisms of human pancreatic polypeptide (hPP) release. Clin Res 1977; 25: 574.

19 Schwartz TW, Rehfeld JF. Mechanism of pancreatic polypeptide release. Lancet 1977; i: 697-8.

20 Schwartz TW, Grotzinger U, Schoon IM, Olbe L. Vagovagal stimulation of pancreatic-polypeptide secretion by graded distention of the gastric fundus and antrum in man. Digestion 1979; 307-14.

21 Fink AS, Floyd JC Jr. Fiddian-Green RG. Release of human pancreatic polypeptide and gastrin in response to intraduodenal stimuli: a case report. Metabolism 1979; 28: $339-42$.

22 Taylor IL. Kauffman GL, Walsh JH, Trout H, Chew P, Harmon JW. Role of the small intestine and gastric antrum in pancreatic polypeptide release. Am J Physiol 1981: 240: G387-91.

23 Wilson RM, Boden G, Owen OE. Pancreatic polypeptide responses to a meal and to intraduodenal amino acids and sodium olcate. Endocrinology 1978; 102: 859-63.

24 Adrian TE, Bloom SR, Besterman HS, Barnes AJ, Cooke JJC, Russel KCG. Mechanism of pancreatic polypeptide release in man. Lancet 1977; i: 161-3.

25 Flaten O, Myren J. Adrenergic modulation of the release of pancreatic polypeptide after intraduodenal and oral glucose in man. Scand J Gastroenterol 1981; 16: $781-7$. 
26 Flaten O. Tronier B. Dose-dependent increase in concentrations of gastric inhibitory polypeptide and pancreatic polypeptide after small amounts of glucose intraduodenally in man. Scand J Gastroenterol 1982; 17: 677-80.

27 Schwartz TW, Rehfeld JF, Stadil F, Larsson LI, Chance RE, Moon N. Pancreatic polypeptide response to food in duodenal ulcer patients before and after vagotomy. Lancet 1976; i; $1102-5$.

28 Taylor IL, Impicciatore M, Carter DC, Walsh JH. Effect of atropine and vagotomy on pancreatic polypeptide response to a meal in dogs. Am J Physiol 1978; 235: E443-7.

29 Dimitriadis G, Tessari P, Go V, Gerich J. Effects of acarbose on metabolic and hormonal responses to meal injection and intravenous glucose in normal man. In: Creutzfeldt W, ed. Proceedings of the First International Symposium on Acarbose. Amsterdam; Excerpta Medica, 1982: 216-22.

30 Fogel MR, Gray GM. Starch hydrolysis in man: an intraluminal process not requiring membrane digestion. J Appl Physiol 1973; 35: 263-7.

31 DiMagno EP. Go VLW, Summerskill WHJ. Relations between pancreatic enzyme outputs and malabsorption in severe pancreatic insufficiency. $N$ Engl J Med 1973; 288: $813-5$.

32 Malagelada J-R, Rees WDW, Mazzotta LJ, Go VLW. Gastric motor abnormalities in diabetic and postvagotomy gastroparesis: effect of metoclopramide and bethanechol. Gastroenterology 1980): 78: 286-93.

33 Floyd JC Jr, Fajans SS, Pek S, Chance RE. A newly recognised pancreatic polypeptide; plasma levels in health and discase. Recent Progr Horm Res 1977: 33: 519-70.

34 Christofides ND. Sarson DL. Albuquerque RH, et al. Release of gastrointestinal hormones following an oral water load. Experimentia 1979; 35: 1521-3.

35 Levitt NS, Vinik AI, Sive AA, van Tonder S. Lund A. Impaired pancreatic polypeptide responses to insulininduced hypoglycemia in diabetic autonomic neuropathy. J Clin Endocrinol Metab 1980; 50: 445-9.

36 Hanafusa $T$. Toyoshima $H$. Nonaka $K$. Tarui $S$. Impaired response of human pancreatic polypeptide to insulin induced hypoglycemia in insulin-dependent diabetics. Horm Metab Res 1981; 19: 1-5.

37 Hilsted J, Madsbad S, Krarup T, et al. No response of pancreatic hormones to hypoglycemia in diabetic autonomic neuropathy. J Clin Endocrinol Metab 1982; 54: 815-9.

38 Krarup T, Schwartz TW. Hilsted J, Madsbad S, Verlacge O, Sestoft L. Impaired response of polypep- tide to hypoglycemia: an carly sign of autonomic neuropathy in diabetes. Br Med J 1979; ii: 1.544-6.

39 White NH, Gingerich RL, Levandoski LA, Cryer PE, Santiago JV. Plasma pancreatic polypeptide response to insulin-induced hypoglycemia as a marker for defective glucose counterregulation in insulin-dependent diabetes mellitus. Diabetes 1985; 34: 9.

40) White NH, Skor D. Cryer PE. Bier DM. Levandoski L. Santiago JV. Identification of type I diabetic patients at increased risk for hypoglycemia during intensive therapy. N Engl J Med 1983; 308: 485-91.

41 McGrath BP. Stern AI, Esler M. Hansky J. Impaired pancreatic polypeptide release to insulin hypoglycacmia in chronic autonomic failure with posturnal hypotension: evidence for parasympathetic dysfunction. Clin Sci 1982; 63: 321-3.

42 Polinsky RJ, Taylor IL, Chew P, Weise V, Kopin IJ. Pancreatic polypeptide responses to hypoglycemia in chronic autonomic failure. J Clin Endocrinol Metab 1982; 54: 48-52.

43 Floyd JC. Fajans SS, Pek S. Physiologic regulation of plasma levels of PP in man. In: Bloom SR, ed. Gut hormones. New York: Churchill Livingstone, 1978: 24753.

44 McConnell JG, Alam MJ, O’Hare MMT, Buchanan KD. Stout RW. The effect of age and sex on the response of enteropancreatic polypeptides to oral glucose. Age Ageing 1983; 12: 54-62.

45 Lonovics T. Gutzman S, Devitt P, et al. Release of pancreatic polypeptide in humans by infusion of cholecystokinin. Gastroenterology 1980; 79: 817-22.

46 Meyer FD, Gyr K, Hacki W, et al. The release of pancreatic polypeptide by CCK-octapeptide and some analogues in the dog. Gastroenterology 1981; 80: 742-7.

47 Amland PF, Jorde R, Aanderud S, Burhol PG, Giercksky K-E. Effects of intravenously infused porcine GIP on serum insulin, plasma C-peptide, and pancreatic polypeptide in non-insulin-dependent diabetes in the fasting state. Scand J Gastroenterol 1985; 20: 315-20.

48 Yoshiya K. Yamamura T. Ishikawa Y, et al. Effect of truncal vagotomy on intestinal phase of pancreatic polypeptide release in dogs. Regul Pept 1985; 11 : 143-8.

49 Adrian TE, Bloom SR, Hermansen K, Iversen J. Pancreatic polypeptide, glucagon and insulin secretion from the isolated perfused canine pancreas. Diabetologia 1978; 14: 413-7.

50 Amland PF, Jorde R, Burhol PG, Gicrcksky K-E. Effects of atropine on GIP-induced insulin and pancreatic polypeptide release in man. Scand J Gastroenterol 1985; 20: 321-4. 